\title{
Nature-based flood protection: using vegetated foreshores for reducing coastal risk
}

\author{
Vincent Vuik ${ }^{1,2, a}$, Sebastiaan N. Jonkman ${ }^{1}$ and Saskia van Vuren ${ }^{2,1}$ \\ ${ }^{1}$ Delft University of Technology, Civil Engineering and Geosciences, P.O. Box 5048, 2600 GA, Delft, The Netherlands \\ ${ }^{2}$ HKV Consultants, P.O. Box 2120, 8203 AC, Lelystad, The Netherlands
}

\begin{abstract}
Vegetated foreshores such as salt marshes, mangrove forests and reed fields can reduce wave loads on coastal dikes due to depth-induced wave breaking and wave attenuation by vegetation. Here we present field measurements of wave propagation over salt marshes during severe storm conditions, a modelling approach to describe the effect of vegetated foreshores on wave loads on the dike, and a probabilistic model to quantify the effect of vegetated foreshores on failure probabilities of the dike due to wave overtopping.
\end{abstract}

\section{Introduction}

Coastal flood risk reduction by creating and restoring eco-systems is increasingly seen as a promising supplement to conventional coastal engineering methods (e.g. [1]). Salt marshes, mangrove forests and reed fields can act as a vegetated foreshore in front of a coastal dike. In such a combined dike-foreshore system, the foreshore plays a role in attenuating storm waves, whereas the dike retains the surge and the remaining wave energy. The current study focuses on this type of (eco)systems.

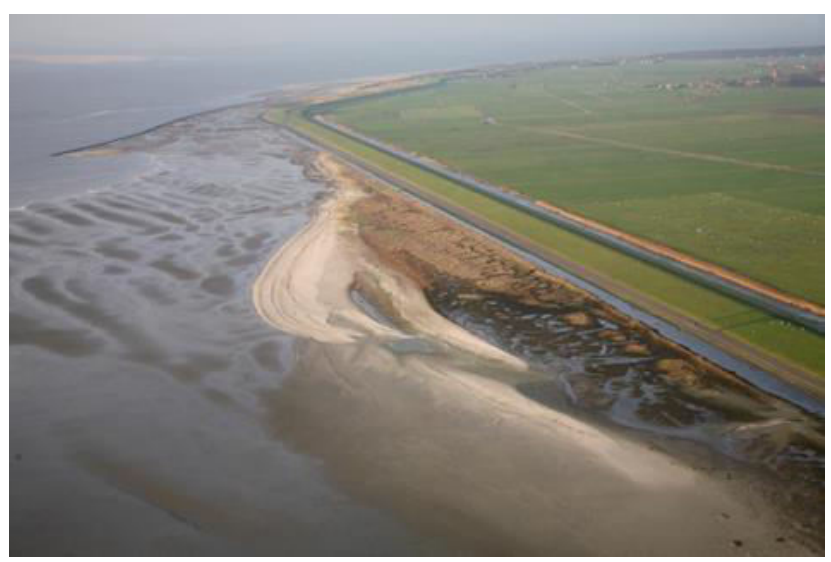

Figure 1. Example of a vegetated foreshore along a Wadden Sea dike in the Netherlands

Large-scale implementation of vegetated foreshores in flood risk policy is still lacking worldwide. This has a number of reasons. Firstly, mechanistic descriptions of relevant physical processes are mainly based on moderate conditions, with small water depths and low waves. And

\footnotetext{
a Corresponding author: V.Vuik@tudelft.nl
}

secondly, ecosystems are characterized by a relatively high degree of uncertainty with respect to spatial and temporal variations. Quantification of these uncertainties is required for determining the efficiency and reliability of a vegetated foreshore as a component of the flood management system.

\section{Methods}

Here we present field measurements of wave propagation over several salt marshes in the Netherlands, collected during severe storms starting from the autumn of 2014. The measurements include periods with high water depths (up to $2 \mathrm{~m}$ above the salt marsh surface) and the largest wave heights reported in literature so far for field measurements on salt marshes (up to $0.8 \mathrm{~m}$ significant wave height).

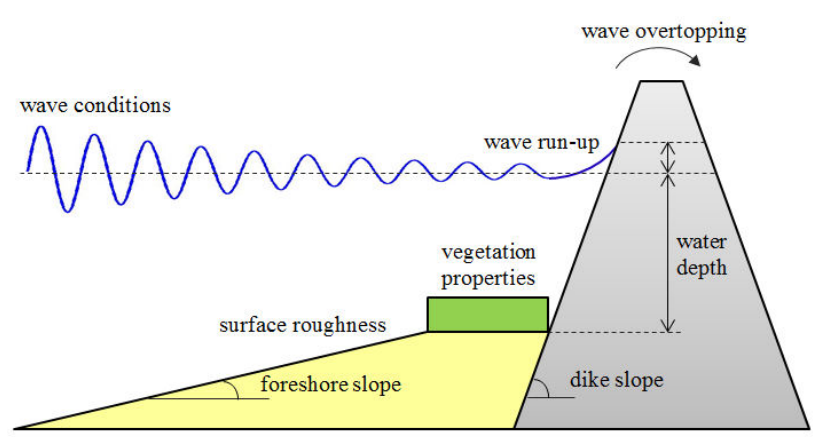

Figure 2. Schematic view of dike-foreshore system

The wave measurements are used for two objectives. Firstly, the data is exploited for calibrating and validating 
a wave model (SWAN), which describes wave energy dissipation on vegetated foreshores by depth-induced wave breaking, bottom friction and wave attenuation by vegetation [2]. Secondly, the data is used for defining probability density functions of relevant parameters that describe wave propagation over vegetated foreshores.

The study considers dike failure due to excessive wave overtopping. This study focuses on the quantification of uncertainties for all parameters that govern the wave transformation on the vegetated foreshore, such as the elevation and cross-shore length of the foreshore, the height, diameter and stem density of the vegetation, stem breakage due to wave action, and model parameters like the vegetation bulk drag coefficient and the breaker parameter (Figure 2). By incorporating all probability distributions in the wave overtopping computations, a new model (Figure 3) is developed, which is able to compute a probability of failure of a combined dikeforeshore system.

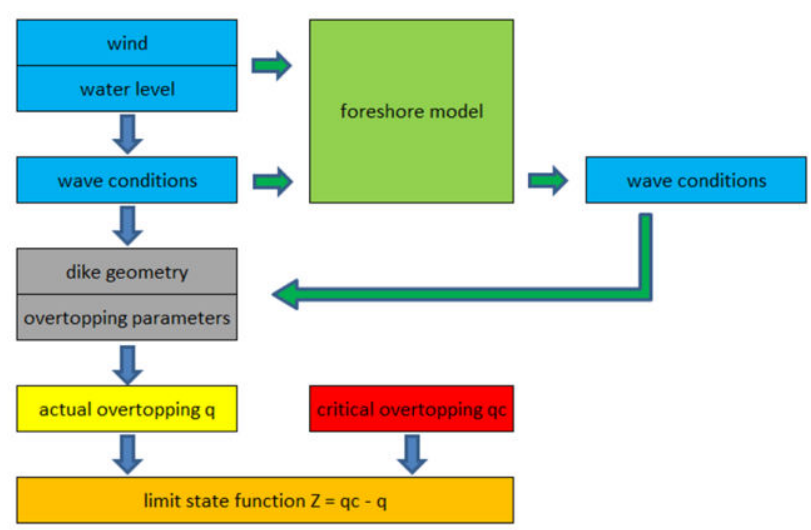

Figure 3. Set-up of probabilistic model, in which the foreshore model is used to compute the change in wave conditions over the vegetated foreshore (Figure 2)

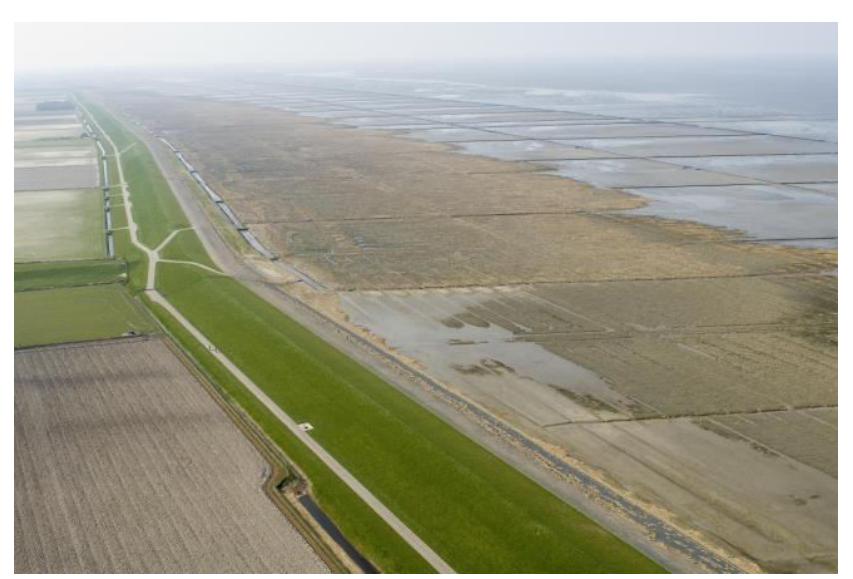

Figure 4. Salt marshes along the Wadden Sea dike (Source: https://beeldbank.rws.nl, Rijkswaterstaat)

\section{Results}

The probabilistic model has been applied to a Wadden Sea dike in the north of the Netherlands, with salt marshes in front (Figure 4), as an illustration of the applicability and added value of the probabilistic approach. The study shows how and how much the probability of failure due to wave overtopping is affected by the presence of a vegetated foreshore (Figure 5).

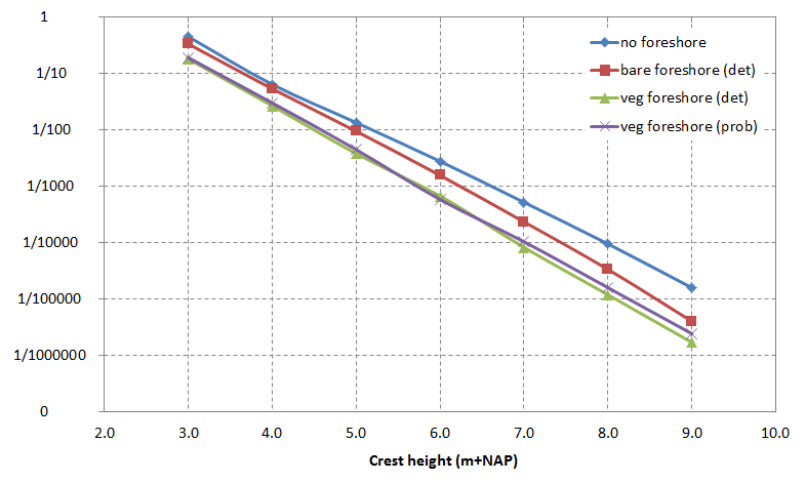

Figure 5. Example of the computation of a failure probability per year as a function of the crest height of the dike, for the situation without foreshore (blue), with a bare foreshore (red), with a vegetated foreshore (green) and with a vegetated foreshore, where also uncertainties in foreshore characteristics and models involved were taken into account (purple).

It should be noted that the effect of the foreshore is already partly present in the probability of failure 'without foreshore' (blue line) in Figure 5, as the wave conditions to assess the dike were computed with a SWAN model, for locations at a distance of approximately $100 \mathrm{~m}$ from the dike [3]. When wave breaking on the foreshore is taken into account more accurately (red line), lower failure probabilities are computed. If the additional effect of salt marsh vegetation is considered, failure probabilities are reduced even further, also when uncertainties in the functioning of the vegetated foreshore are taken into account. For this computations, the properties of winter state Spartina anglica were applied.

Some (site-specific) conclusions:

- Although the water depth on the salt marshes increases for higher return periods, the efficiency of the foreshore does not decrease. This is because of the depth-limitation of the wave heights in the Wadden Sea. When water depths increase, wave heights increase as well, which makes the foreshore effective for the full range of water depths.

- The effect of vegetation is larger than the uncertainty involved, which makes vegetation a valuable component of the foreshore system. It should be noted that preliminary probability density functions have been used, and that a more detailed 
quantification of uncertainties and correlations will be subject to further research.

- The effect of stem breakage due to severe wave action, and the effect of variable grazing regimes was not included in this study.

Additionally, the study demonstrates the relative importance of various parameters and uncertainties involved. This relative importance of a parameter depends on the sensitivity of the failure probability to the variation in the probability distribution of that particular parameter. In this way, the study demonstrates which parameters, processes and models should be subject to further research, in order to decrease the probability of failure of the combined dike-foreshore system.

It appeared that for low crest heights (and relatively high failure probabilities) uncertainties in the geometry of the dike, geometry of the foreshore and vegetation properties were dominant. For high crest heights, model uncertainties for the overtopping discharge, wave breaking and the incident wave period become the dominant uncertainties. That means that for very low failure probabilities, uncertainties in the exact state of the foreshore become less important than uncertainties in the models that describe the system. Uncertainties in incident (offshore) wave height cancel more or less out, because higher waves experience relatively high dissipation on the foreshore. This is in agreement with [4].

The results of the study can be applied by dike managers for quantifying and maintaining the benefits of existing salt marshes in front of the dikes, or for cost-efficient design, construction and maintenance of new foreshores.

\section{Acknowledgements}

This work is part of the research programme BE SAFE, which is financed by the Netherlands Organisation for Scientific Research (NWO). Additional financial support has been provided by Deltares, Boskalis, Van Oord, Rijkswaterstaat, World Wildlife Fund and HZ University of Applied Science.

\section{References}

1. Temmerman, S., Meire, P., Bouma, T.J., Herman, P.M.J., Ysebaert, T., and De Vriend, H.J. (2013). Ecosystem-based coastal defence in the face of global change. Nature, 504, 79-83.

2. Vuik, V., Jonkman, S.N., Borsje, B.W. and Suzuki, T. (2016). Nature-based flood protection: the efficiency of vegetated foreshores for reducing wave loads on coastal dikes. Journal of Coastal Engineering doi: 10.1016/j.coastaleng.2016.06.001

3. Gautier, C., \& Groeneweg, J. (2012). Achtergrondrapportage hydraulische belasting voor zee en estuaria. Technical report, Deltares (in Dutch).

4. Van Wesenbeeck, B. K., de Boer, W., Narayan, S., van der Star, W. R., and de Vries, M. B. (2016). Coastal and riverine ecosystems as adaptive flood defenses under a changing climate. Mitigation and Adaptation Strategies for Global Change, 1-8. 